\title{
Evaluation of the Impact of the Additional Mass of an Innovative AC System on the Overall Energy Consumption of a Battery Electric Vehicle in Tropical Climate
}

\author{
Srikkanth Ramachandran ${ }^{1}$, Alison Subiantoro ${ }^{2}$, Ooi Kim Tiow ${ }^{3}$ \\ ${ }^{1,2}$ TUM CREATE (Technical University of Munich - Campus for Research Excellence And Technological Enterprise), \\ ${ }^{3}$ School of Mechanical and Aerospace Engineering, Nanyang Technological University
}

\begin{abstract}
One of the major issues concerning the inclusion of additional components in vehicle for its efficiency improvement is the increase in mass of the vehicle. The increased mass causes an increased energy demand for propulsion of the vehicle. This paper aims at analyzing the impact of the added mass of an innovative air conditioning system powered by bio-ethanol based auxiliary power unit on the overall energy use of electric vehicles that are designed for the tropical climate of Singapore.
\end{abstract}

Keywords - Automotive air conditioner, auxiliary power unit, dehumidification system, electric vehicle.

\section{INTRODUCTION}

The hot and humid conditions of tropical countries like Singapore make air conditioning (AC) an absolute necessity in vehicles. It is estimated that $\mathrm{AC}$ systems consume close to $30 \%$ of the traction battery energy in a battery electric vehicle (BEV) [1]. Hence, to achieve long ranges for BEVs driven in tropical conditions, there is a need to develop AC systems with improved efficiencies.

The 'Air Conditioning and Power Management' department of TUM CREATE Limited is developing an autonomous AC system to address the issue of air conditioning of electric vehicles in Singapore. Our AC systems shall include a dehumidifier and an expander compressor unit (ECU) for improving its efficiency. It also includes a bio-ethanol based auxiliary power unit (APU) for making it autonomous.

Dehumidification System: AC systems have to perform two major functionalities, viz. dehumidification and cooling. Singapore being located in a tropical region has an average ambient temperature of $27^{\circ} \mathrm{C}$ and average ambient relative humidity of $84 \%$ [2]. From the range suggested by ASHRAE for thermal comfort $\left(22-26^{0} \mathrm{C}\right.$ at $30-60 \%$ relative humidity) [3], the desired cabin conditions were chosen to be $23^{\circ} \mathrm{C}$ and $60 \%$ relative humidity. Considering cooling of the air from ambient conditions to the desired cabin conditions, the sensible hear ratio (SHR) and latent heat ratio (LHR) are found to be 0.16 and 0.84 respectively. This implies that dehumidification shall consume more energy than cooling.
The conventional AC system which does dehumidification of air by cooling of it to temperatures below the dew point temperature is inefficient for such climatic conditions. Hence a solid state desiccant based dehumidification system is being developed by us for removal of moisture from the air. The dehumidifier utilizes silica gel based desiccants that are synthesized to have low regeneration temperatures. The heat required for regeneration of the desiccants shall come from the waste heat of the APU. The other advantage of having a desiccant based dehumidification system is that the evaporator could operate at higher temperatures thus increasing the coefficient of performance (COP) of the AC system. An air cooler is used to cool down the temperature of the hot and dry air exiting the dehumidifier.

$E C U$ : In conventional car $\mathrm{AC}$ systems, the power of expansion is not recovered since the expansion is done using a throttle valve. Inclusion of a separate expander to recover this expansion power increases the weight and the cost of the system. However, we are developing an innovative ECU where the expander and compressor are integrated into one machine. The work recovered from the expansion process reduces the power required by the compressor and increases the COP of the AC system. Additional information about the design and working of the ECU could be found in [4], [5].

$A P U$ : The AC system being developed shall be powered by an APU which uses bio-ethanol as its fuel, thus making it independent of the main traction battery. The APU consists of an ethanol storage tank, coupled to an ethanol reformer and an ethanol-reformate based high temperature proton exchange membrane (HT PEM) fuel cell stack. Bio-ethanol has been chosen as the fuel of choice for the following reasons

a) Sustainable source;

b) Low global greenhouse gas (GHG) emissions;

c) High energy density.

Since the organic sources for production of bio-ethanol (Municipal Solid Waste (MSW)) are limited in Singapore, the bio-ethanol based APU is just restricted to the AC system and not extended to the entire vehicle. 
(a)

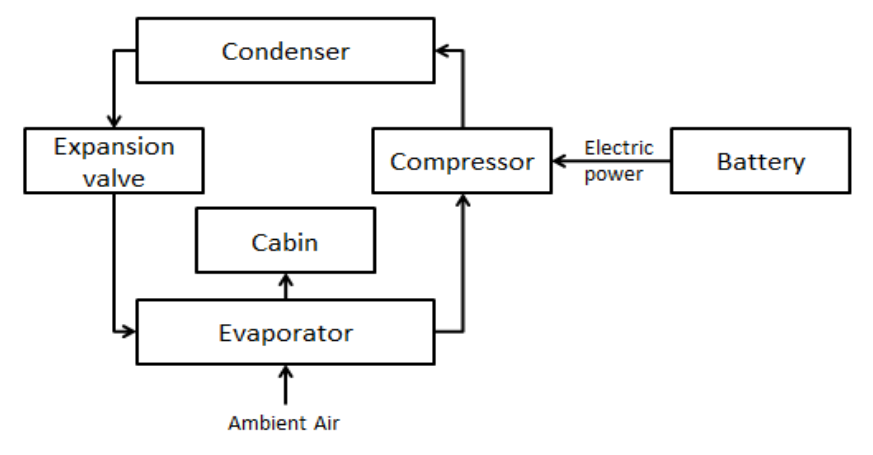

(b)

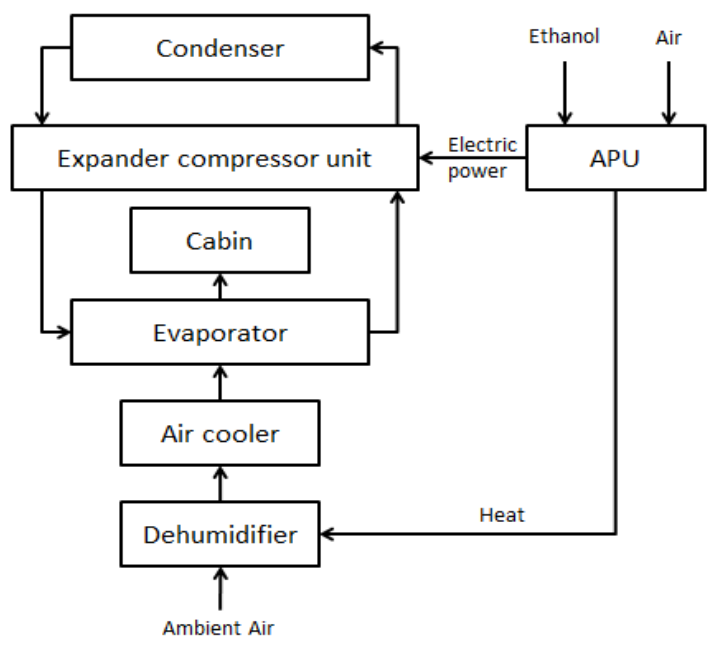

Fig. 1. (a) The schematic representation of a conventional AC system and (b) The schematic representation of our autonomous AC system.

The schematic representation of the conventional system and the new autonomous AC system are shown in Fig.1 (a) and (b) respectively.

Issues associated with the autonomous AC system: Since we are adding new components to the AC system, we shall be increasing the mass of the vehicle. Hence the driving energy required at the wheels which is directly proportional to the mass of the vehicle shall increase as well. However, a part of this energy shall be compensated by the reduction of $\mathrm{AC}$ system's load on the battery due to the inclusion of the autonomous AC system which operates at higher efficiencies. This paper aims at analyzing the impact of the combination of the above mentioned two factors on the overall energy use of the vehicle. This paper shall be helpful in understanding whether addition of additional mass to vehicle for achieving improved system/sub-system efficiencies makes sense from vehicles overall energy consumption point of view.

\section{METHODOLOGY}

There are two approaches to this analysis, both of which shall be discussed in this paper.

1) Fixed battery size: Assuming that the battery size is maintained the same and that the AC system is powered by the APU, more energy from the battery could be utilized for driving. Hence, the driving range increases. However, the increase in the range will not be directly proportional to the increased capacity because of the increased mass of the vehicle. The influence of additional mass of the autonomous AC system on the incremental range shall be studied in this section.

2) Fixed range of BEV: If we fix the range of the vehicle, the battery could be downsized by inclusion of the autonomous AC system since the AC system's energy requirements will be supplied by the APU. The combined effect of the increased mass of the autonomous AC system and the decreased mass in battery on the overall energy use of the vehicle shall be analyzed in this section of the study.

For estimating the size of the battery required to drive the vehicle, we need to find out the energy demands of the vehicle. The varied loads on the vehicles are:

i) AC load;

ii) Auxiliary load;

iii) Driving/Mechanical Load.

Fig. 2 shows the block diagram of the overall simulation set up. The AC system is connected to the Battery or APU by dotted lines to indicate that only one of the sources would be used for powering it. Battery will be used in the conventional system and APU will be used in the autonomous system. The double headed arrow indicates the bidirectional flow of energy, i.e. battery-to-wheels during driving and wheel-tobattery during recuperation.

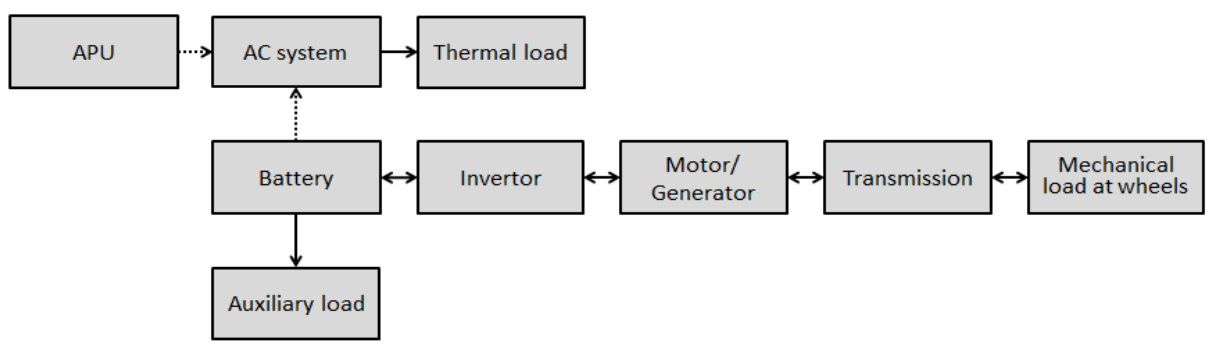

Fig. 2. Schematic representation of the simulation set up. 


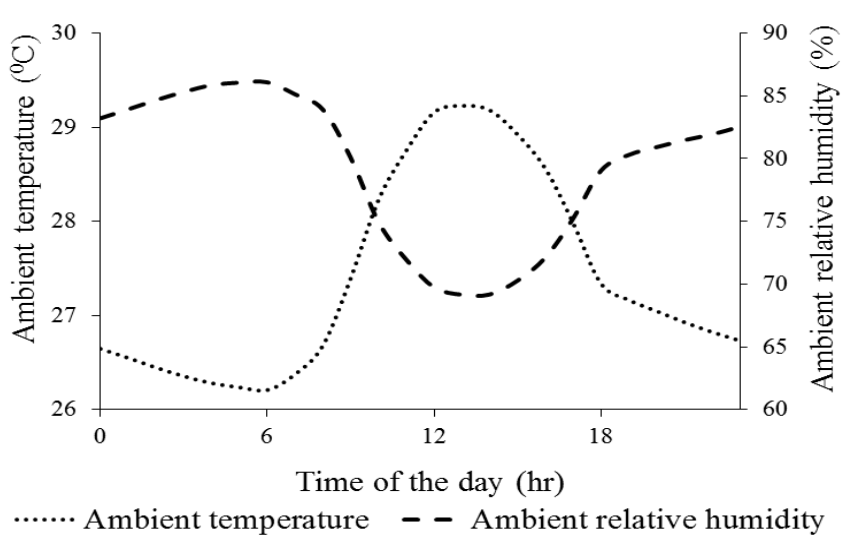

Fig. 3. Mean ambient temperature and humidity of Singapore.

The amount of power required by the AC system depends on the climatic conditions and the COP of the AC system. The hourly data of the Singapore's climatic conditions could be found in Fig. 3. This data represents the mean hourly climatic data of Singapore for the period of 5 years (2008-2012). Fig. 4 represents the global horizontal radiation of Singapore. The values represent the amount of solar radiation reaching the vehicle which is pre corrected by the cloud and building shading factors. The weather data used is from NASA [6] and was processed in [7].

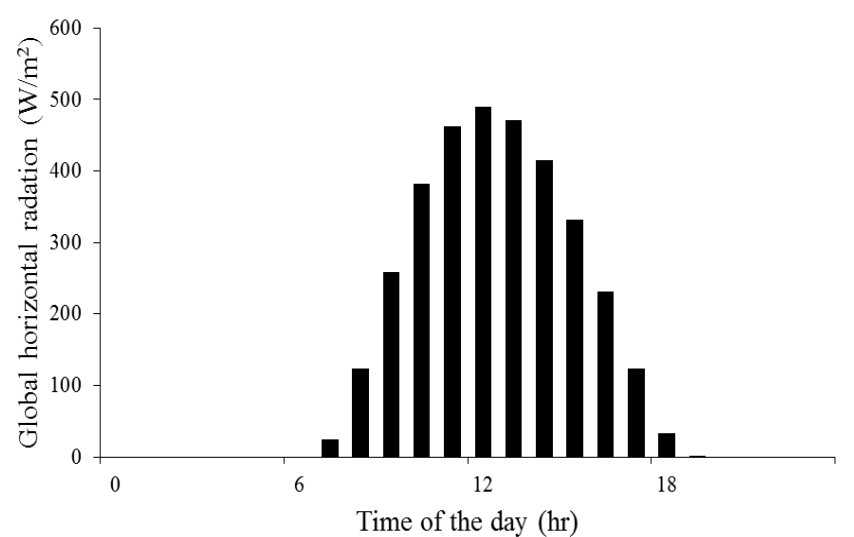

Fig. 4. Mean global horizontal radiation of Singapore.

The four major sources of heat load in vehicle are passenger heat load, conduction by car body, solar radiation and air exchange. The average occupancy of car in Singapore is 1.7 [8]. Since the BEV is being developed to serve as a taxi, we assume a slightly higher occupancy of 2 . It is assumed that there are 2 passengers $(n)$, each emitting $150 \mathrm{~W}$ [9] of heat into the cabin. The passenger heat load $\left(Q_{\text {pass }}\right)$ is calculated as,

$$
Q_{\text {pass }}=n \cdot 150
$$

For simplicity, the surface temperature $\left(t_{b o d y}\right)$ of the car is assumed to be the same as the ambient temperature. The thermal conductivity $\left(k_{\text {body }}\right.$ ) value used for the body is 1.257 $\mathrm{W} / \mathrm{m}^{2} \mathrm{~K}$ and conducting surface area $\left(A_{\text {body }}\right)$ is $3 \mathrm{~m}^{2}$. The heat load caused by car body conduction $\left(Q_{\text {cond }}\right)$ is given by,

$$
Q_{\text {cond }}=k_{b o d y} \cdot A_{b o d y} \cdot\left(t_{b o d y}-t_{c a b}\right)
$$

where ' $t_{c a b}$ ' is the cabin temperature.

The area of car window exposed to solar irradiation $\left(A_{\text {win }}\right)$ is fixed to be $2 \mathrm{~m}^{2}$. The glass window transmittance coefficient $\left(\kappa_{\text {win }}\right)$ is taken to be 0.75 . The heat load in cabin due to solar radiation $\left(Q_{\text {solar }}\right)$ is given by,

$$
Q_{\text {solar }}=I_{\text {solar }} \cdot A_{\text {win }} \cdot \kappa_{\text {win }}
$$

where, ' $I_{\text {solar }}$ ' represents global horizontal radiation.

The amount of heat load caused by air exchange depends on the type of AC system in use. The cooling and dehumidification process in the conventional AC system and our new AC system is represented in the psychrometric chart shown in Fig 5. Processes 1-2-5 represent the cooling and dehumidification process of a convention AC system. Since the conventional AC system does dehumidification by cooling the air to temperatures below dew point, the thermal load of air exchange of the conventional system $\left(Q_{\text {air,conv }}\right)$ shall be,

$$
Q_{\text {air }, \text { conv }}=\dot{m}_{\text {air }} \cdot\left(h_{1}-h_{2}\right)
$$

where ' $\dot{m}_{\text {air }}$ ' represents the mass flow of air which is assumed to be $0.06 \mathrm{~kg} / \mathrm{s}$ and ' $h_{1}$ ' and ' $h_{2}$ ' represents enthalpy of point 1 and 2 in Fig. 5 respectively.

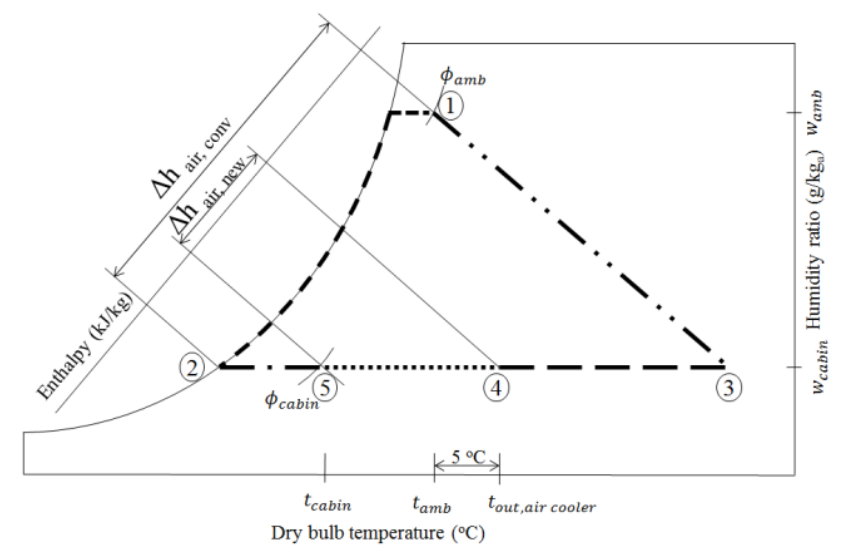

Fig. 5. Air cooling and dehumidification process in the conventional and new AC system.

The proposed AC system does dehumidification by a desiccant based dehumidification system. This is represented by the process $1-3$ in Fig. 5. Process 3-4 in Fig. 5 represents the cooling of hot dry air exiting the dehumidifier in an air cooler. The air is cooled to a temperature $\left(t_{4}\right)$ which is $5^{\circ} \mathrm{C}$ above the ambient air temperature. Therefore, the thermal load of air exchange of the new AC system $\left(Q_{\text {air,new }}\right)$ shall be,

$$
Q_{\text {air,new }}=\dot{m}_{\text {air }} \cdot\left(h_{4}-h_{5}\right)
$$

where, ' $h h_{4}$ ' and ' $h_{5}$ ' represents enthalpy of point 4 and 5 in the Fig. 5. 
The total thermal load on the evaporator $\left(Q_{\text {evap }}\right)$ is

$$
Q_{\text {evap }}=Q_{\text {pass }}+Q_{\text {cond }}+Q_{\text {solar }}+Q_{\text {air }}
$$

For converting the heat load into electrical load, we need the COP values. The COP values of both the conventional and new AC system are calculated based on the pressure enthalpy (p-h) diagram shown in Fig. 6. The refrigerant is assumed to enter the expander at a temperature $10^{\circ} \mathrm{C}$ lower than condenser temperature $\left(t_{\text {cond }}\right)$ and enter the compressor $\left(t_{\text {comp,in }}\right)$ at cabin temperature. The efficiency of compressor and the ECU is taken to be $60 \%$. The refrigerant used in our system is R134a. The dotted lines on the $\mathrm{p}$-h diagram represent the new AC system. The evaporator temperatures of the conventional and new system ( $t_{\text {evap,conv, }} t_{\text {evap,new }}$ ) are assumed to be $7^{\circ} \mathrm{C}$ lower than the dew point temperature $\left(t_{D}\right)$ and cabin temperature respectively. The expansion process in expansion valve is isenthalpic.

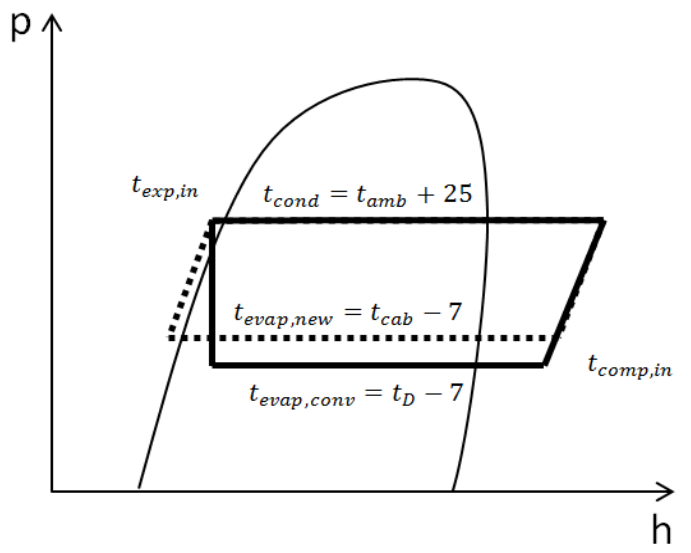

Fig. 6. Pressure enthalpy diagram of the conventional and new refrigeration cycles.

The COP and the electrical power requirement of the conventional and the new AC system are calculated and plotted in Fig. 7.

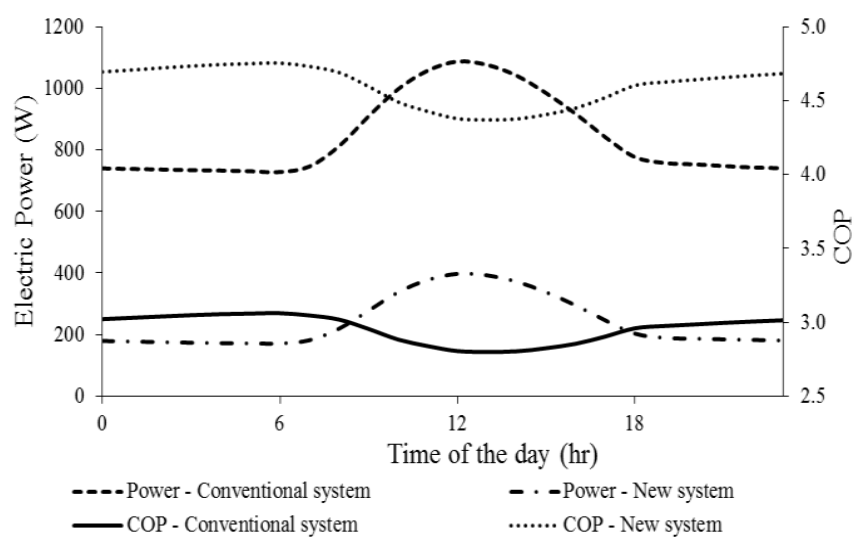

Fig. 7. Electrical power requirement and $\mathrm{COP}$ of the conventional and new AC systems.

The mean power requirement of the conventional and the new AC system are calculated to be $839 \mathrm{~W}$ and $241 \mathrm{~W}$ respectively. Since our load calculations are based on average hourly data, the system needs to be overpowered to cater extreme conditions.

Additional mass of the AC system: It is evident from the schematics shown in Fig. 3 that the additional weight of the new AC system shall come from the dehumidifier, ECU and APU. The ECU being developed is estimated to have an additional mass of not more than $10 \%$ of and existing automotive AC compressor which is estimated to weigh around $10.2 \mathrm{~kg}$ [10]. Hence, the ECU could cause about $1 \mathrm{~kg}$ increase in weight. The mass of the dehumidification system to be added is estimated to be about $8-9 \mathrm{~kg}$. The design of the APU is approximated to be similar to a commercially available ethanol based APU from ZSW, Germany. It weighs $80 \mathrm{~kg}$, has an ethanol tank, a steam reformer and a PEM FC stack which is capable of providing $1 \mathrm{~kW}$ of electric and $2 \mathrm{~kW}$ of thermal power [11]. As suggested earlier, the APU is oversized to be able to work in extreme conditions including startups (i.e. immediately after parking). Hence a total mass of approximately $90 \mathrm{~kg}$ needs to be added to the vehicle. To allow a more thorough analysis, a sensitivity analysis was done around this additional mass $(70-110 \mathrm{~kg})$. The inclusion of dehumidification system and ECU has a significant impact on the sizing of the APU since it reduces the peak power demands by about one third. In the absence of dehumidifier, the APU would be about 3 times heavier.

The average auxiliary load on the vehicle which comprises of devices like head lights, tail lamps, blower fans, coolant pumps, etc. is taken to be $500 \mathrm{~W}$.

The BEV being developed at TUM CREATE Limited is designed to have a driving range of $200 \mathrm{~km}$ using batteries. Good specific energy, lack of memory effect and slow selfdischarge rates when not in use make lithium-ion batteries a suitable choice for our BEV [12]. To calculate the amount of energy required to drive the vehicle through the $200 \mathrm{~km}$, we calculated the energy required at wheels and back calculated it to the battery through the drivetrain path efficiencies. The power demand at the wheel was calculated using MATLAB simulations based on the following formulae [13]:

$$
\begin{gathered}
P_{a c c l}=m_{v e h} \cdot v \cdot a \cdot f_{r o t} . \\
P_{a d}=0.5 \cdot c_{w} \cdot A_{f} \cdot \rho \cdot v^{3} . \\
P_{r o l l}=f \cdot m_{v e h} \cdot g \cdot \cos \theta \cdot v . \\
P_{i n c}=m_{v e h} \cdot g \cdot \operatorname{Sin} \theta \cdot v . \\
P_{t o t a l, w h e e l}=P_{a c c l}+P_{a d}+P_{r o l l}+P_{i n c} .
\end{gathered}
$$

where, ' $P_{\text {accl }}$ ', ' $P_{\text {ad }}$ ', ' $P_{\text {roll }}$ ', ' $P_{\text {inc }}$ ' and ' $P_{\text {total, wheel }}$ represent the power required for acceleration, power required to overcome 
air drag, power required to overcome rolling resistance, power required to climb incline and total power required at wheels respectively. The total mass of the vehicle is given by ' $m_{v e h}$ ' and the slope of the road is given by ' $\theta$ ', which is assumed to be zero. The acceleration and velocity of the vehicle are represented by ' $a$ ' and ' $v$ ' respectively. The definition of the other variables used in the equation and their values used in simulation are given in Table 1.

From the above formulae (7)-(11), it is clear that the power demand of the vehicle is dependent on drive cycle (time dependent speed, acceleration and slope values), the vehicle form (shape) and vehicle mass. Though the first two factors of the vehicle are fixed, the mass of the vehicle is dependent on the presence or the absence of APU based new AC system. We assume a kerb mass of $1100 \mathrm{~kg}$ [14] which includes the conventional AC system, car body, window, seats, etc. but excludes battery and passenger weight. The efficiencies of the components of the drivetrain considered are shown in Table1.

Iterative mass estimation: The total mass of the vehicle is the summation of passenger's mass, kerb mass, battery mass and the additional mass of the autonomous AC system. Two passengers with an average weight of $62 \mathrm{~kg} /$ person [15] were assumed. The mass of the battery was determined by the amount of energy required by the AC system, auxiliaries and driving. However, we see from the equations (7)-(11) that the mass of the battery itself (which affects the mass of the vehicle) affects the energy demand. Hence, there was a necessity for iterative solving to achieve the right size of the battery for the required range. This was realized using MATLAB scripts. The basic configurations of the vehicle considered in this simulation are shown in Table 1 [16]. The usable State of Charge (SOC) range of the battery is assumed to by $0.7(0.2-0.9)$ and the energy density of the battery is taken to be $120 \mathrm{Wh} / \mathrm{kg}$ [14].

TABLE 1

VARIABLES USED FOR SIMULATION

\begin{tabular}{|l|c|c|c|}
\hline Variable & Symbol & Value & Units \\
\hline Air drag coefficient & $c_{w}$ & 0.31 & {$[-]$} \\
\hline Coefficient of rolling resistance & $f$ & 0.011 & {$[-]$} \\
\hline Frontal area & $A_{f}$ & 2.2 & $\mathrm{~m}^{2}$ \\
\hline Rotational inertial coefficient & $f_{\text {rot }}$ & 1.1 & {$[-]$} \\
\hline Density of air & $\rho$ & 1.225 & $\mathrm{~kg} / \mathrm{m}^{3}$ \\
\hline Acceleration due to gravity & $g$ & 9.81 & $\mathrm{~m} / \mathrm{s}^{2}$ \\
\hline Efficiency - Battery & $\eta_{\text {bat }}$ & 0.95 & {$[-]$} \\
\hline Efficiency - Inverter & $\eta_{\text {inv }}$ & 0.97 & {$[-]$} \\
\hline Efficiency - Motor/Generator & $\eta_{\text {mot }}$ & 0.95 & {$[-]$} \\
\hline Efficiency - Transmission & $\eta_{\text {trans }}$ & 0.95 & {$[-]$} \\
\hline
\end{tabular}

The drive cycle used for the evaluation is the Singapore taxi drive cycle (STDC). The STDC is developed internally at TUM CREATE by Mr. Pablo Hidalgo of the Interdisciplinary Development of Vehicle Concepts' department based on the GPS data collected from Singaporean taxis. The drive cycle lasts for $1310 \mathrm{~s}$ and covers a distance of $7.75 \mathrm{~km}$ at an average speed of $21.3 \mathrm{~km} / \mathrm{hr}$. The drive cycle is shown in Fig. 8 .

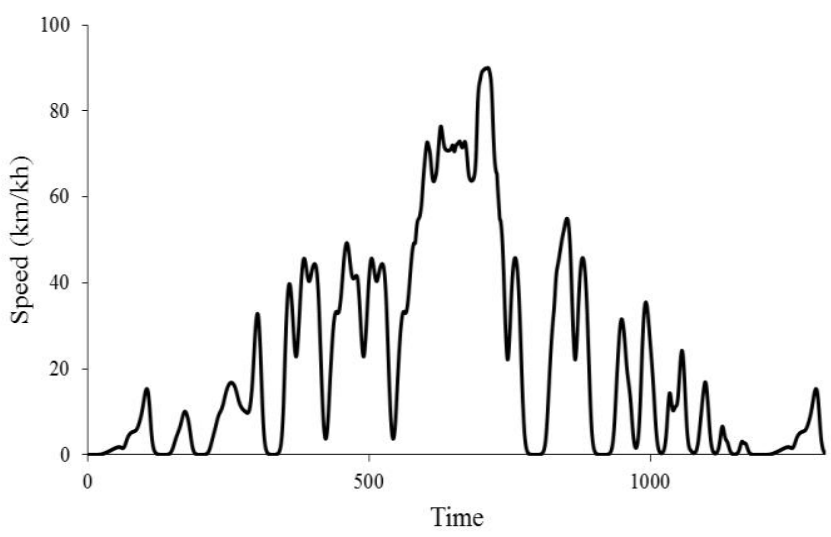

Fig. 8. Speed vs Time plot of the Singapore Taxi Drive Cycle.

In the fixed battery size approach, we calculated the battery size required for covering $200 \mathrm{~km}$ with conventional $\mathrm{AC}$ system. Then with this battery size and the new AC system powered by APU, we calculated the additional range achievable. We also calculated the energy consumption per $\mathrm{km}$ of this extended range and compared it to the original value.

In the fixed range approach, we fixed the range of the vehicle, compared the battery weight and energy use from battery per km with the conventional and the new AC system.

\section{RESULT AND ANALYSIS}

Initial simulation results suggest that the amount of energy required for driving $200 \mathrm{~km}$ range in Singapore using the STDC for nominal conditions with the conventional AC system powered by battery is $34 \mathrm{kWh}$. This amount of energy corresponds to $407 \mathrm{~kg}$ of lithium ion battery. AC system consumes close to $23 \%$ of the total energy. The total weight of the vehicle is $1507 \mathrm{~kg}$ and the energy consumption per $\mathrm{km}$ is $171 \mathrm{Wh} / \mathrm{km}$ or $17 \mathrm{kWh} / 100 \mathrm{~km}$. For the ease of analysis, the energy usage from the battery is split into 2 parts,

i) Energy use of AC system - $39 \mathrm{Wh} / \mathrm{km}$;

ii) Energy use for driving and auxiliaries $-132 \mathrm{Wh} / \mathrm{km}$;

For making a fair comparison of the vehicles with and without the autonomous AC system, we compared only the energy use from driving and auxiliaries (i.e. the non AC part). Henceforth, the term energy consumption refers to the non AC part alone.

\section{A. Fixed Battery Size Approach}

In this part of the analysis, the size of the battery was fixed to the original $407 \mathrm{~kg}$, providing a total energy of $34 \mathrm{kWh}$. Now we introduce the autonomous AC system, thus making more energy from battery available for driving. The weight of the vehicle is now increased by $90 \mathrm{~kg}$ because of the additional components of the new AC system. The simulation of the vehicle in this configuration suggests that the total range of the vehicle will increase to $251 \mathrm{~km}$, which corresponds to about $26 \%$ range extension. Hence inclusion of an autonomous AC system in electric vehicles makes sense from range extension point of view. However, this range is achieved at efficiencies of $136 \mathrm{Wh} / \mathrm{km}$, which is $4 \mathrm{Wh} / \mathrm{km}$ higher than the driving and 
auxiliaries energy consumption of the original vehicle. This increase is mainly attributed to the increase in mass of the vehicle.

The impact of additional mass on the range extension capability and energy consumption per $\mathrm{km}$ of the BEV is studied and plotted in Fig. 9. The additional achievable range decreases from $53 \mathrm{~km}$ to $49 \mathrm{~km}$ for increase in an additional weight from 70 to $110 \mathrm{~kg}$ whereas the energy consumption per $\mathrm{km}$ increases from $135 \mathrm{Wh} / \mathrm{km}-137 \mathrm{Wh} / \mathrm{km}$ for the same range of additional mass.

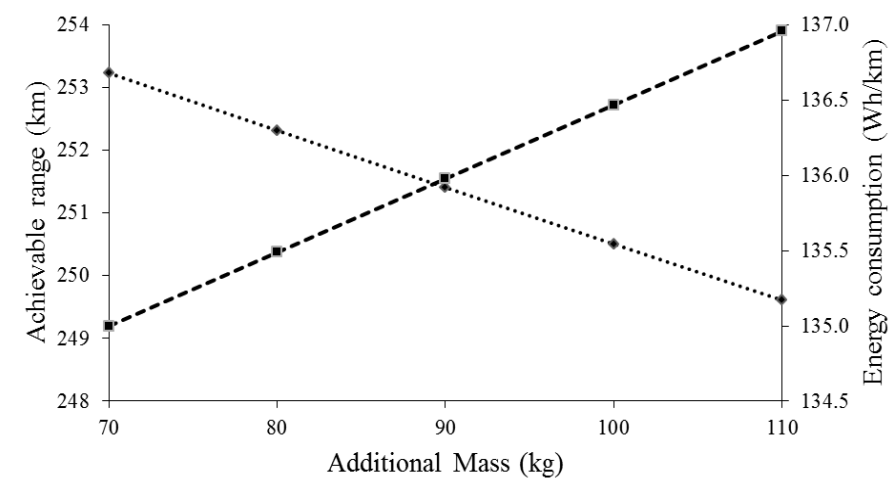

Fig. 9. The energy consumption and achievable range of the BEV with fixed battery size with inclusion of the autonomous APU plotted against variable additional mass.

With inclusion of autonomous AC system, the range of the BEV increases by about $25-27 \%$. Though this is achieved at lower efficiencies, it tackles one of the key disadvantages of the $\mathrm{BEV}$ which is its range. In addition to that, since the range per recharge has increased, the number of recharges required in the BEVs life cycle decreases. The lifetime of a battery depends on the number of charge-recharge cycles it has gone through. Since we shall reduce the number of cycles the battery goes through, we shall increase the lifetime of a BEV which is a considerable advantage.

\section{B. Fixed Range Approach}

In this approach, the range of the vehicle is fixed to $200 \mathrm{~km}$ and the impact of inclusion of the autonomous AC system is studied. By inclusion of the autonomous AC system, the power consumption from the battery goes down and hence the battery could be downsized for achieving the same range. The simulation result suggests that by the inclusion the autonomous AC system (with a weighs of $90 \mathrm{~kg}$ ), the size of the battery could be reduced to $313 \mathrm{~kg}$ from its original value of $407 \mathrm{~kg}$. This corresponds to about $23 \%$ reduction in battery mass. However, the total reduction in mass of the vehicle shall be $4 \mathrm{~kg}$ only. The BEV would be able to traverse $200 \mathrm{~km}$ at an energy consumption rate of $131 \mathrm{Wh} / \mathrm{km}$ which is lower than the original energy consumption rate of $132 \mathrm{Wh} / \mathrm{km}$. Hence inclusion of and autonomous AC system makes sense both in terms of reduced battery size and energy consumption.

Fig. 10 shows the impact of additional mass of the autonomous AC system on the reduction in size of the battery and the energy consumption rates. It is seen that for additional weights (of the AC system) which are greater than $94 \mathrm{~kg}$, the energy consumption rate of the BEV with autonomous $\mathrm{AC}$ system is higher than that of the conventional ones. To understand this, we need to analyze the cause of reduction in the battery size entirely.

The reduction in size of the battery is caused by the compounded effect of the following 2 factors:

i) Reduction in power demand from the AC system since it has been made autonomous;

ii) Change in mass of the vehicle which causes a change in its mechanical energy demand.

Hence, as long as the AC system remains autonomous and the summation of the incremental mass of the autonomous APU system and the mass of the reduced battery is less than the mass of the original battery, the energy consumption rates shall be lower than the original value due to the compounded effect of the above two factors. This breakeven occurs at $94 \mathrm{~kg}$ of additional mass. The inference drawn here is that if the additional mass is lesser than $94 \mathrm{~kg}$, it will lead to an improvement in energy consumption rate.

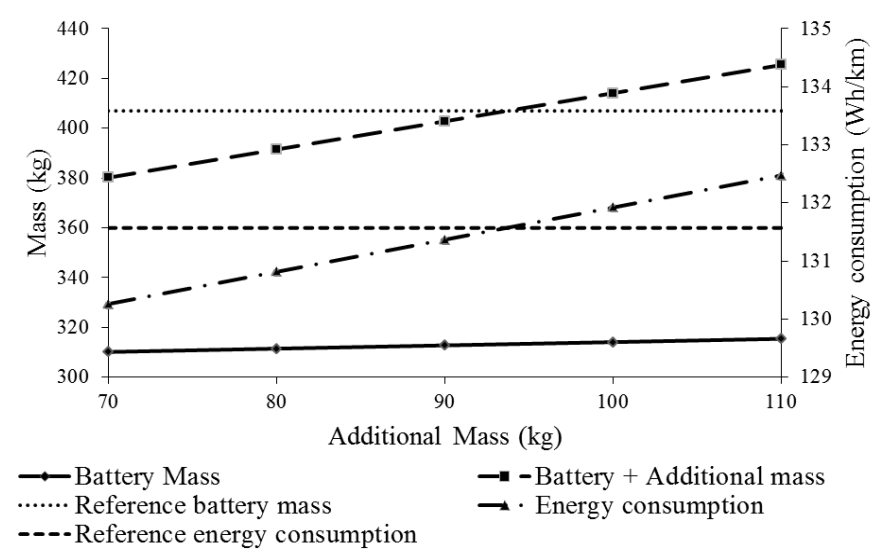

Fig. 10. The energy consumption and battery mass of a BEV with fixed range upon inclusion of the Autonomous APU plotted against variable additional mass.

The important factor that works in favor of downsizing the battery keeping the range constant is the reduction in recharge time. Longer recharge times per driving range is another major drawbacks of a BEV. In the BEV with autonomous $\mathrm{AC}$ system, the time taken to refill ethanol tank is negligible as compared to the time taken for recharging of the battery. Hence battery recharge time is the limiting factor. Therefore, even if we have additional masses which are greater than 94 $\mathrm{kg}$, the downsizing of the battery still provides us an advantage in terms of reduced recharge time per driving range. The reduction in battery mass ranges from $24 \%$ for $70 \mathrm{~kg}$ additional weight to $22 \%$ for $110 \mathrm{~kg}$ additional weight. Hence even for the worst case scenario of $110 \mathrm{~kg}$ additional mass provides us significant advantage it terms of reduced charging times per driving range. Especially since TUM CREATE Limited is designing the BEV to function as a taxi, reduced charging times are very essential. 


\section{CONCLUSION}

The following conclusions could be drawn from this study:

- Inclusion of autonomous AC system could increase the driving range by $25-27 \%$ if the battery mass is kept constant.

- The autonomous AC system could reduce the battery mass by $22-24 \%$ if the range is kept constant.

- The energy consumption rates of the BEV with autonomous AC system are lower than the conventional vehicle as long as the additional mass is less than $94 \mathrm{~kg}$ in the fixed range configuration.

Having an autonomous AC system in BEV vehicles driven in tropical conditions makes sense from energy consumption, recharge time and battery life time point of view.

\section{ACKNOWLEDGEMENT}

This work was financially supported by the Singapore National Research Foundation under its Campus for Research Excellence and Technological Enterprise (CREATE) program.

\section{REFERENCES}

[1] Farrington, R., Rugh, J., Impact of Vehicle Air-Conditioning on Fuel Economy, Tailpipe Emissions and Electric Vehicle Range, NREL/CP540-28960 presented at Earth Technologies Forum, Washington DC, October 2000.

[2] National Environmental Agency, Singapore, "Weather Statistics", [Online] Available http://app2.nea.gov.sg/weather-climate/climateinformation/weather-statistics, [Accessed: Dec. 14, 2014].

[3] ASHRAE. Thermal Environmental Conditions for Human Occupancy. ASHRAE Standard, 2004(STANDARD 55):30, 2004

[4] K S Yap, K T Ooi, A Chakraborty, Introduction of the Novel Cross Vane Expander-Compressor Unit for Vapour Compression Cycle, International Compressor Engineering Conference, 2014, Purdue e-Pubs, Paper no. 2253.

[5] K S Yap, K T Ooi, A Chakraborty, Modelling and Simulation of the Dynamics of Cross Vane Expander-Compressor Unit for Vapour Compression, International Compressor Engineering Conference, 2014, Purdue e-Pubs, Paper no. 2257.
[6] Rienecker, M.M., M.J. Suarez, R. Gelaro, R. Todling, J. Bacmeister, E. Liu, M.G. Bosilovich, S.D. Schubert, L. Takacs, G.-K. Kim, S. Bloom, J. Chen, D. Collins, A. Conaty, A. da Silva, et al. (2011), MERRA: NASA's Modern-Era Retrospective Analysis for Research and Applications. J. Climate, Vol. 24, pp 3624-3648, July 2011 http://dx.doi.org/10.1175/jcli-d-11-00015.1

[7] K. Janker. Wind and PV power generation time series (to be published). Chair for Energy Economy and Application Technology, Technische Universität München, München, Germany, 2013.

[8] Land Transport Authority, Singapore, "Lessons from Bus Operations", 2006. [Online] Available http://www.lta.gov.sg/ltaacademy/doc/Lessons\%20from\%20Bus\%20Op erations\%20REV5.pdf, [Accessed: Dec. 14, 2014].

[9] ISO 7730: Ergonomics of the thermal environment - Analytical determination and interpretation of thermal comfort using calculation of the PMV and PPD indices and local thermal comfort criteria, 2005.

[10] SAE International, "Air-conditioning system For Electric Vehicles (iMiEV)", SAE Automotive Refrigerant\& System Efficiency Symposium 2010. [Online] Available http://www.sae.org/events/aars/presentations/2010/W2.pdf, [Accessed: Dec. 14, 2014].

[11] Zentrum für Sonnenenergie- und Wasserstoff-Forschung, "Ethanol reforming 1 kWel Fuel Cell System", 2012. [Online] Available http://www.zsw-bw.de/uploads/media/ZSW_EtOHSystem_01.pdf, [Accessed: Dec. 14, 2014].

[12] N. Omar, M Daowd, O Hegazy, G Mulder, J M Timmermans, T Coosemans, PV D Bossche and J V Mierlo, "Standardization Work for BEV and HEV Applications: Critical Appraisal of Recent Traction Battery Document", J. Energies, vol. 5, pp138-156, Jan 2012. http://dx.doi.org/10.3390/en5010138

[13] Robert Bosch GmbH, Automotive Handbook, 2011, pp 664

[14] S. Campanari, G. Manzolini, and F. Garcia de la Iglesia, "Energy analysis of electric vehicles using batteries or fuel cells through well-towheel driving cycle simulations," J. Power Sources, vol. 186, no. 2, pp. 464-477, Jan. 2009. http://dx.doi.org/10.1016/j.jpowsour.2008.09.115

[15] S C Walpole, D P Merino, P Edwards, J Cleland, G Stevens and I Roberts, "The weight of nations: an estimation of adult human biomass", BMC Public Health 2012, vol. 12: pp 439, Jun 2012.

[16] S. Ramachandran, "Development of Automotive Application Relevant Dynamic Ragone Charts", Master's Thesis, Technische Universität München, München, Germany, 2013. 